\title{
Article \\ Characterization of the Volatile Profile of Cultivated and Wild-Type Italian Celery (Apium graveolens L.) Varieties by HS-SPME/GC-MS
}

\author{
Samantha Reale ${ }^{1} \mathbb{D}$, Valter Di Cecco ${ }^{2}$, Francesca Di Donato ${ }^{1} \mathbb{D}$, Luciano Di Martino ${ }^{2} \mathbb{D}$, Aurelio Manzi ${ }^{2}$, \\ Marco Di Santo ${ }^{2}$ and Angelo Antonio D'Archivio ${ }^{1, *(D)}$
}

1 Dipartimento di Scienze Fisiche e Chimiche, Università degli Studi dell'Aquila, Via Vetoio, 67100 L'Aquila, Italy; samantha.reale@univaq.it (S.R.); francesca.didonato3@graduate.univaq.it (F.D.D.)

2 Majella Seed Bank-Parco Nazionale della Majella, Via Badia 28, 67039 Sulmona, Italy; valter.dicecco@parcomajella.it (V.D.C.); luciano.dimartino@parcomajella.it (L.D.M.); aureliomanzi1963@gmail.com (A.M.); marco.disanto@parcomajella.it (M.D.S.)

* Correspondence: angeloantonio.darchivio@univaq.it

check for updates

Citation: Reale, S.; Di Cecco, V.; Di Donato, F.; Di Martino, L.; Manzi, A.; Di Santo, M.; D'Archivio, A.A. Characterization of the Volatile Profile of Cultivated and Wild-Type Italian Celery (Apium graveolens L.) Varieties by HS-SPME/GC-MS. Appl. Sci. 2021, 11, 5855. https://doi.org/ 10.3390/app11135855

Academic Editor: Robert J. Meier

Received: 20 May 2021

Accepted: 22 June 2021

Published: 24 June 2021

Publisher's Note: MDPI stays neutral with regard to jurisdictional claims in published maps and institutional affiliations.

Copyright: (c) 2021 by the authors. Licensee MDPI, Basel, Switzerland. This article is an open access article distributed under the terms and conditions of the Creative Commons Attribution (CC BY) license (https:/ / creativecommons.org/licenses/by/ $4.0 /)$.

\begin{abstract}
Celery (Apium graveolens L.) is a vegetable belonging to the Apiaceae family that is widely used for its distinct flavor and contains a variety of bioactive metabolites with healthy properties. Some celery ecotypes cultivated in specific territories of Italy have recently attracted the attention of consumers and scientists because of their peculiar sensorial and nutritional properties. In this work, the volatile profiles of white celery "Sedano Bianco di Sperlonga" Protected Geographical Indication (PGI) ecotype, black celery "Sedano Nero di Torricella Peligna" and wild-type celery were investigated using head-space solid-phase microextraction combined with gas-chromatography/mass spectrometry (HS-SPME/GC-MS) and compared to that of the common ribbed celery. Exploratory multivariate statistical analyses were conducted using principal component analysis (PCA) on HS-SPME/GC-MS patterns, separately collected from celery leaves and petioles, to assess similarity/dissimilarity in the flavor composition of the investigated varieties. PCA revealed a clear differentiation of wild-type celery from the cultivated varieties. Among the cultivated varieties, black celery "Sedano Nero di Torricella Peligna" exhibited a significantly different composition in volatile profile in both leaves and petioles compared to the white celery and the prevalent commercial variety. The chemical components of aroma, potentially useful for the classification of celery according to the variety/origin, were identified.
\end{abstract}

Keywords: celery; volatile profile; solid phase microextraction; gas-chromatography; wild-type celery; discrimination

\section{Introduction}

Celery (Apium graveolens L.) is a biennial plant belonging to the Apiaceae (Umbrelliferae) botanical family and has been used since ancient times for medicinal purposes by the Greeks, Chinese, Egyptians, and Romans [1]. Despite it being documented that celery was already cultivated in Roman times, domestication and selection of different varieties for the table began in Italy only in the 16th-17th centuries [2]. Among the cultivated celery species, the variety "dulce", grown worldwide and appreciated for the aniseed taste of its crispy petioles, is nowadays the most economically important [3]. Celery petioles are generally consumed fresh in salads, or together with leaves and are used in the preparation of soups and other hot meals. Celery is also an ingredient in various condiments used to flavor dishes in traditional cuisine and gastronomy. The wild form of Apium graveolens grows in humid soils, such as brackish ditches, by rivers and in other damp locations, especially near the sea in saltmarshes, but is also found in inland areas as the result of rewilding of cultivated varieties. Compared to the cultivated variety, the plant of wild celery is frailer, 
with thinner roots and petioles, has a reduced fleshiness and exhibits more coriaceous, aromatic and bitter leaves [2].

Apart from being a low-caloric food and rich in minerals, celery is a source of natural active substances, including phenolic acids, flavonoids, and vitamins [4-8], and can exert many curative and preventive physiological functionalities, such as lowering cholesterol levels [9], anti-inflammatory activity [10], antimicrobial activity [11], anticancer activity [12], and anti-depressant activity [13].

The characteristic flavor of celery petioles result from combination of a wide range of volatile compounds released during chewing, including terpenes, phthalides, esters, and aldehydes $[3,14,15]$. Despite preference by consumers being closely related to the organoleptic profile, the influence of the geographical origin and/or variety of celery on its sensorial properties has not fully investigated. More generally, only a few studies reported on the relationship between celery composition and cultivar and/or origin. In particular, the natural bioactive component profiles in the petioles and leaves of four Chinese celery cultivars were analyzed by high-performance liquid chromatography coupled to mass spectrometry (HPLC-MS) and, together with their antioxidant activities, were compared [16]. Recently, proton $\left({ }^{1} \mathrm{H}\right)$ NMR spectroscopy [17] was applied to investigate the differences between celery extracts from three geographical origins: Australia, Taiwan, and China. Sugars, amino acids, and organic acids were found to contribute significantly to the differentiation between origins, with mannitol identified as an important discriminating metabolite.

Development of approaches for the identification of variety/origin becomes particularly pertinent for the valorization of niche cultivars grown in restricted territories by rural communities, because it offers the possibility of preventing consumers and producers from commercial fraud and encourages farmers to safeguard the uniqueness of local ecotypes.

In this work, we investigated the volatile profiles of petioles and leaves of two celery ecotypes, the white celery "Sedano Bianco di Sperlonga" and black celery "Sedano Nero di Torricella Peligna". The white celery "Sedano Bianco di Sperlonga" is a Protected Geographical Indication (PGI) ecotype [18,19], cultivated within the territory in the municipalities of Fondi and Sperlonga (LT, Lazio, Central Italy). Its characteristic light color is an intrinsic element of this ecotype, which may be intensified by a denser planting pattern. The black celery "Sedano Nero di Torricella Peligna" is grown in the area of Torricella Peligna ( $\mathrm{CH}$, Abruzzo, Central Italy) close to the territory of the Majella National Park which is active in the preservation of the local germplasm and promotion of the sustainable economic development of rural areas through the re-discovery and commercial valorization of autochthone cultivars $[20,21]$. The volatile profiles of these two celery ecotypes are compared with that of wild celery accessions collected from the coastal area of the Abruzzo Region (Punto Ferruccio, Ortona $\mathrm{CH}$ ) and that of the prevalent commercial variety of ribbed celery, available in the Italian market.

The volatile profile of celery was investigated using a headspace-solid phase microextraction (HS-SPME) technique coupled to gas-chromatography with mass-spectrometry detection (GC-MS). HS-SPME/GC-MS is widely and ever increasingly used in volatile sampling and analysis of a great variety of complex matrices, including plants, food and environmental matrices [22-24]. The semi-quantitative HS-SPME/GC-MS characterization of volatile profiles in plants can be particularly useful for discriminating between species, cultivars, varieties, or even between different ripening stages, cultivation conditions, or harvesting times, as well as in food matrices for authentication and quality control. Compared to conventional extraction methods, HS-SPME is simple, fast (as it requires little or no sample preparation) and it is both a pre-concentration and extraction technique. Furthermore, being a solventless technique, it avoids artifacts and solvent contamination. Additionally, compared to hydro-distillation, HS-SPME can prevent the thermal degradation of volatiles and provide a more realistic and accurate description of the aroma composition, which more closely reflects the sensorial properties as they are perceived by the consumer $[14,25]$. Eventually, explorative principal component analysis (PCA) was carried out on the aroma profiles to provide information on the differences due to the celery variety and harvesting 
time, and to identify which volatile components are significant for the discrimination of the origin/variety.

\section{Materials and Methods}

\subsection{Celery Samples}

Samples of the black celery "Sedano Nero di Torricella Peligna" (BC), harvested in June 2019 and August 2020, were kindly donated by local producers. The samples of white celery "Sedano Bianco di Sperlonga" Protected Geographical Indication (PGI) ecotype (WC) were purchased from a vegetable shop in February and July 2020. Accessions of wild-type celery (WTC) were collected from Punto Ferruccio near Ortona $(\mathrm{CH}, \mathrm{Abruzzo}$, Central Italy) in July 2019. The samples of common ribbed celery (CC), i.e., the prevalent commercial variety available in Italian markets, were purchased from a supermarket in July 2019 and in February 2020. All celery samples were frozen at $-20^{\circ} \mathrm{C}$. After defrosting at room temperature for one hour, $110-120 \mathrm{mg}$ of chopped pietoles or leaves were placed in a $4 \mathrm{~mL}$ vial with a screw cap, equipped with a Mininert Valve (Supelco, Bellefonte, PA, USA) and subjected to HS-SPME.

\subsection{Head Space-Solid Phase Microextraction (HS-SPME)}

The SPME fiber used in this work was coated with divinylbenzene/carboxen/polydim ethylsiloxane (DVB/CAR/PDMS), 50/30 $\mu \mathrm{m}$ thickness (Supelco, Bellefonte, PA, USA). The fiber was introduced in the vial equipped with the Mininert cap and exposed for 5 min to the head space of the sample kept in a water bath at $35^{\circ} \mathrm{C}$. After extraction of the celery volatiles, the fiber was inserted into the injection port of the GC apparatus where desorption took place at $250^{\circ} \mathrm{C}$ for $2 \mathrm{~min}$. After each analysis, the fiber was kept in the GC injection port at $270{ }^{\circ} \mathrm{C}$ for $5 \mathrm{~min}$ and after that a blank run was recorded to check the cleaning of the sorbent.

\subsection{GC-MS Analysis}

All the analyses were carried out on a Saturn 2000 GC-MS instrument (Varian, Inc. Palo Alto, CA, USA). The GC apparatus was equipped with a 1078 split/splitless injector with a SPME liner inside. All injections were performed in split mode with a 10:1 split ratio.

A Varian FactorFour ${ }^{\mathrm{TM}}$ VF5-ms capillary column (5\% phenyl-95\% polymethylsiloxane, $30 \mathrm{~m} \times 0.25 \mathrm{~mm} \times 0.25 \mu \mathrm{m}$ film thickness) was used and the carrier gas was helium IP supplied at a flow rate of $1.1 \mathrm{~mL} / \mathrm{min}$. GC separation was achieved using the following column oven temperature program: initial temperature $50^{\circ} \mathrm{C}$ for $2 \mathrm{~min}$, then increased to $200{ }^{\circ} \mathrm{C}$ at $6{ }^{\circ} \mathrm{C} / \mathrm{min}$ and then to $280^{\circ} \mathrm{C}$ at a rate of $65^{\circ} \mathrm{C} / \mathrm{min}$, the final temperature being held for $1.8 \mathrm{~min}$. The EI-ion trap mass spectrometer operated at the following conditions: ionization energy $70 \mathrm{eV} ; 40-600 \mathrm{~m} / \mathrm{z}$ range; $1 \mathrm{~s}$ scan cycle time; transfer line temperature $170{ }^{\circ} \mathrm{C}$; manifold temperature $110^{\circ} \mathrm{C}$; ion trap temperature $150{ }^{\circ} \mathrm{C}$. The compounds were identified by comparison of their retention indices and mass spectra with those reported in standard libraries [26] or in the specialized literature [27].

\subsection{Data Analysis}

Multivariate GC-MS chromatograms of both celery leaves and petioles were handled by principal component analysis (PCA) to assess the similarity/dissimilarity in the aroma composition among the different varieties. PCA [28] allows to represent multivariate data in a low-dimensionality space of mutually orthogonal, thus uncorrelated, principal components (PCs). They can be defined as the linear combination of original variables explaining unrelated portions of information. Transformation of the original data matrix $\mathbf{X}$ is described by Equation (1):

$$
\mathbf{X}=\mathbf{T} \mathbf{P}^{\mathrm{T}}+\mathbf{E}
$$

The loading matrix $\mathbf{P}$ (with dimension $\mathrm{VxA}$, where $\mathrm{V}$ is the original variables and A the number of principal components) defines the new directions. The scores matrix $\mathrm{T}$ (SxA, where $\mathrm{S}$ is the number of samples and A the number of principal components) 
expresses the coordinates of the samples in the PC space. The error matrix $\mathbf{E}(\mathrm{SxV}$,$) collects$ the residuals associated with the approximation of the original data with fewer PCs than the original variables. To display multivariate information, objects and loadings can be projected onto the compressed PC subspace; this provides a graphical and straightforward visualization of the trends within the data samples (score plot) and interpretation of the selected PCs in terms of the original variables (loading plot). For exploratory analysis, visualization of the data distribution by considering the scores and loadings plot of just the first components (generally two or three) is informative enough, because loss of useful information is generally negligible. PCA was performed using in-house routines in the MATLAB environment (R2019b; The Mathworks, Natick, MA, USA).

\section{Results}

\subsection{Celery Volatile Profile by HS-SPME/GC-MS}

The volatile compounds identified by HS-SPME/GC-MS in both celery petioles and leaves are reported in Table 1, together with the retention time (RT) and the mean relative $(\%)$ area of the detected volatiles in each variety.

Table 1. Volatile profiles of celery petioles or leaves: observed retention time (RT ( $\mathrm{min})$ ), assigned chemical structure and mean relative (\%) peak area and related standard deviation in the GC/MS chromatograms for each variety: common celery (CC), white celery "Sedano Bianco di Sperlonga" (WC), black celery "Sedano Nero di Torricella Peligna" (BC) and wild type celery (WTC).

\begin{tabular}{|c|c|c|c|c|c|c|c|c|c|}
\hline \multirow[b]{2}{*}{ RT (min) } & \multirow[b]{2}{*}{ Compound } & \multicolumn{2}{|c|}{$\mathrm{CC}$} & \multicolumn{2}{|c|}{ WC } & \multicolumn{2}{|c|}{ BC } & \multicolumn{2}{|c|}{ WTC } \\
\hline & & Petioles & Leaves & Petioles & Leaves & Petioles & Leaves & Petioles & Leaves \\
\hline 6.65 & $\alpha$-Thujene & $0.96 \pm 1.07$ & $0.08 \pm 0.02$ & $1.00 \pm 1.03$ & $0.17 \pm 0.13$ & $0.51 \pm 1.09$ & $0.12 \pm 0.46$ & $0.09 \pm 0.03$ & $0.05 \pm 0.04$ \\
\hline 6.85 & $\alpha$-Pinene & $3.68 \pm 2.67$ & $1.21 \pm 0.53$ & $1.44 \pm 1.17$ & $0.35 \pm 0.13$ & $0.54 \pm 0.15$ & $0.22 \pm 0.14$ & $0.40 \pm 0.13$ & $0.14 \pm 0.08$ \\
\hline 7.39 & Camphene & $0.68 \pm 0.50$ & $0.27 \pm 0.10$ & $0.32 \pm 0.31$ & $0.07 \pm 0.04$ & $0.07 \pm 0.02$ & $0.03 \pm 0.19$ & $0.08 \pm 0.03$ & $0.03 \pm 0.01$ \\
\hline 7.83 & Sabinene & $0.59 \pm 0.13$ & $0.17 \pm 0.06$ & $0.51 \pm 0.09$ & $0.16 \pm 0.10$ & $0.88 \pm 0.39$ & $0.47 \pm 0.37$ & $0.26 \pm 0.07$ & $0.14 \pm 0.10$ \\
\hline 7.98 & $\beta$-Pinene & $3.32 \pm 3.41$ & $0.59 \pm 0.44$ & $4.37 \pm 3.47$ & $1.05 \pm 1.07$ & $1.85 \pm 1.82$ & $0.37 \pm 1.11$ & $1.78 \pm 1.06$ & $0.86 \pm 0.66$ \\
\hline 8.21 & $\beta$-Myrcene & $4.18 \pm 3.02$ & $12.52 \pm 12.49$ & $2.36 \pm 0.23$ & $7.32 \pm 4.56$ & $10.98 \pm 3.89$ & $37.31 \pm 13.34$ & $46.20 \pm 6.96$ & $69.51 \pm 0.69$ \\
\hline 9.16 & $p$-Cymene & $6.77 \pm 3.43$ & $1.99 \pm 1.23$ & $5.08 \pm 2.83$ & $1.41 \pm 0.47$ & $12.14 \pm 3.91$ & $3.75 \pm 14.16$ & $5.47 \pm 2.47$ & $0.63 \pm 0.34$ \\
\hline 9.27 & Limonene & $48.33 \pm 6.68$ & $47.87 \pm 12.57$ & $55.25 \pm 0.79$ & $51.37 \pm 0.80$ & $45.27 \pm 0.70$ & $46.56 \pm 16.35$ & $38.25 \pm 6.20$ & $22.78 \pm 6.35$ \\
\hline 9.39 & (Z)- $\beta$-ocimene & $10.54 \pm 3.21$ & $26.00 \pm 4.15$ & $11.91 \pm 5.49$ & $30.47 \pm 6.92$ & $0.79 \pm 0.62$ & $0.97 \pm 0.74$ & $3.30 \pm 2.90$ & $2.66 \pm 1.64$ \\
\hline 9.68 & $(E)-\beta$-ocimene & $0.07 \pm 0.06$ & $0.31 \pm 0.15$ & $0.10 \pm 0.09$ & $0.27 \pm 0.13$ & $0.01 \pm 0.01$ & $0.04 \pm 5.72$ & $0.08 \pm 0.07$ & $0.21 \pm 0.13$ \\
\hline 10.01 & $\gamma$-Terpinene & $14.09 \pm 3.01$ & $2.17 \pm 0.49$ & $14.46 \pm 4.72$ & $2.60 \pm 0.88$ & $22.56 \pm 9.51$ & $5.38 \pm 3.87$ & $2.49 \pm 0.84$ & $0.40 \pm 0.24$ \\
\hline 10.73 & Terpinolene & $0.10 \pm 0.06$ & $0.10 \pm 0.04$ & $0.08 \pm 0.06$ & $0.07 \pm 0.03$ & $0.04 \pm 0.02$ & $0.02 \pm 0.01$ & $0.02 \pm 0.00$ & $0.01 \pm 0.00$ \\
\hline 12.04 & $\begin{array}{l}\text { Limonene oxide, } \\
\text { trans- }\end{array}$ & $0.82 \pm 0.58$ & $0.42 \pm 0.41$ & $0.47 \pm 0.28$ & $0.32 \pm 0.11$ & $0.16 \pm 0.11$ & $0.23 \pm 0.16$ & $0.15 \pm 0.10$ & $0.05 \pm 0.04$ \\
\hline 12.51 & $\begin{array}{c}\text { (E,Z)-1,3,5- } \\
\text { Undecatriene }\end{array}$ & $3.52 \pm 3.71$ & $1.21 \pm 0.33$ & $0.75 \pm 0.49$ & $1.20 \pm 0.82$ & $0.17 \pm 0.12$ & $0.58 \pm 0.44$ & $0.59 \pm 0.35$ & $1.55 \pm 1.04$ \\
\hline 14.36 & $\begin{array}{l}\text { 6-Methyl- } \\
\text { hexahydronaph- } \\
\text { thalene }\end{array}$ & $0.05 \pm 0.04$ & $0.07 \pm 0.03$ & $0.02 \pm 0.02$ & $0.05 \pm 0.03$ & $0.01 \pm 0.01$ & $0.01 \pm 0.01$ & $0.01 \pm 0.00$ & $0.01 \pm 0.01$ \\
\hline 16.61 & $\begin{array}{l}\text { trans-Carveyl } \\
\text { acetate }\end{array}$ & $0.02 \pm 0.01$ & $0.08 \pm 0.03$ & $0.02 \pm 0.02$ & $0.10 \pm 0.04$ & $0.02 \pm 0.01$ & $0.01 \pm 0.01$ & $0.01 \pm 0.01$ & $0.02 \pm 0.01$ \\
\hline 16.80 & Carveol ester & - & $0.04 \pm 0.03$ & - & $0.05 \pm 0.05$ & $0.01 \pm 0.00$ & $0.001 \pm 0.018$ & $0.01 \pm 0.00$ & $0.01 \pm 0.01$ \\
\hline 18.61 & $\beta$-Caryophyllene & $1.26 \pm 0.92$ & $2.62 \pm 1.30$ & $0.57 \pm 0.21$ & $1.38 \pm 0.88$ & $2.41 \pm 2.37$ & $1.19 \pm 0.98$ & $0.31 \pm 0.10$ & $0.29 \pm 0.23$ \\
\hline 19.37 & Sesquiterpene (1) & $0.25 \pm 0.16$ & $0.31 \pm 0.13$ & $0.13 \pm 0.05$ & $0.17 \pm 0.09$ & $0.25 \pm 0.04$ & $0.15 \pm 0.11$ & $0.04 \pm 0.02$ & $0.04 \pm 0.03$ \\
\hline 19.75 & Sesquiterpene (2) & $0.02 \pm 0.02$ & $0.33 \pm 0.15$ & $0.02 \pm 0.02$ & $0.22 \pm 0.12$ & $0.03 \pm 0.02$ & $0.04 \pm 0.37$ & $0.07 \pm 0.04$ & $0.12 \pm 0.11$ \\
\hline 20.07 & $\beta$-selinene & $0.39 \pm 0.19$ & $1.27 \pm 0.39$ & $0.60 \pm 0.33$ & $0.92 \pm 0.42$ & $0.53 \pm 0.12$ & $0.66 \pm 0.65$ & $0.18 \pm 0.11$ & $0.11 \pm 0.07$ \\
\hline 20.20 & $\alpha$-selinene & $0.12 \pm 0.06$ & $0.30 \pm 0.09$ & $0.28 \pm 0.41$ & $0.21 \pm 0.09$ & $0.68 \pm 0.04$ & $0.26 \pm 0.13$ & $0.03 \pm 0.02$ & $0.02 \pm 0.02$ \\
\hline
\end{tabular}

Twenty-two volatile organic compounds were identified, although only very few of them exhibited a relative peak area in the chromatograms greater than $1 \%$; generally, eight compounds in the CC and WC samples and only five in the BC and WTC varieties. The 11 monoterpenes found in celery aroma accounted for $90 \%$ or more of the total chromatogram provided by petioles and leaves, respectively. Among monoterpenes, limonene was the most abundant compound in the cultivated celery varieties CC, WC and $\mathrm{BC}$ with a comparable content in leaves and petioles close to $50 \%$ of the total area. By contrast, $\beta$-myrcene was the most abundant one in WTC, reaching $46 \%$ of the mean total area in petioles and $69 \%$ in leaves, while the mean relative content of limonene in the wild form of celery was noticeably lower (about $23 \%$ in leaves and $38 \%$ in petioles) than that observed in the cultivated varieties. Concerning (Z)- $\beta$-ocimene, relatively high mean percentage areas were detected in the chromatograms of petioles $(11-12 \%)$ and 
leaves (26-30\%) of both CC and WC samples, while the observed relative peak areas were much lower in both petioles and leaves of BC (approximately 1\%) and WTC samples (approximately $3 \%$ ).

As regards sesquiterpenes, we found five compounds but only three of them, $\beta$ caryophyllene and $\alpha$ - and $\beta$-selinene, were unequivocally identified based on their mass spectra and retention times. The sum of the peak areas of the five sesquiterpenes reached $5 \%$ in CC leaves at most and was on average slightly higher in leaves (ca. 3\%) than in petioles (ca. $2 \%$ ). The most abundant sesquiterpene was $\beta$-caryophyllene, providing a relative peak area of $1-2 \%$ in the chromatograms collected from petioles and leaves of the cultivated varieties.

Terpenes have a broad ecological role in plants ranging from defense from insects or herbivorous mammals to antifungal or attractant for pollinators, as well as inter and intra specific signaling. In the case of celery, it has been reported [29] that the repellent effect of this plant towards the whitefly Bemisia tabaci depends on limonene and $\beta$-myrcene, that are the most abundant components in its volatile profile

The aroma of celery can be described as fresh, herbal, woody and citrusy and the major contributors to those olfactory notes are terpenes. However, although limonene is the predominant component of celery essential oil, the major contributors to celery aroma are the phthalides (for example sedanolide, sedanenolide and 3-n-buthylphtalide), which are responsible for the peculiar celery herbal and spicy aroma and flavor. [30]. It must be underlined that under our experimental conditions requiring a sampling temperature slightly above the room temperature and a very short extraction time $\left(35^{\circ} \mathrm{C}\right.$ and $5 \mathrm{~min}$, respectively) only the most volatile compounds can be extracted by SPME. Therefore, in the volatile profiles we obtained the phthalide fraction was completely lacking. Nevertheless, our aim was a comparison of different varieties of celery based on their volatile profiles and not an exhaustive description of the celery aroma compounds.

The study of volatile profile is highly informative since the chemical composition is extremely dynamic and is affected by a plethora of factors, including genotype, season, climate, variety, part of the plant under investigation, the geographical region of origin, soil composition, the stage of ripening, the type of cultivation or harvesting and postharvesting [14].

\subsection{Multivariate Statistical Analysis of Petiole Volatile Profiles}

To assess the similarity/dissimilarity in the volatile profiles of the different celery varieties investigated here, PCA was applied separately to the relative (\%) peak areas of the compounds collected from the petioles and leaves.

PCA exploration of the volatile profiles of the celery petioles are shown in Figure 1, reporting the projection of the samples, and Figure 2, displaying the variable loadings, in the space of the first four PCs that accounted for $97 \%$ of the total variance (explained variance, EV). PCA was performed on the centered data, which did not alter the variance of the original variables. A clear separation of the WTC samples along the positive PC1 direction from the cultivated celery varieties can be observed in Figure 1a. This figure also displays a differentiation, approximately along PC2, of both WC and CC samples collected in June and in February. In addition, PC2 seems to describe a variability internal to the BC group. The four BC samples located in the second quadrant of the PC1-PC2 plane, in particular, come from outer petioles having a darker green color and being more fibrous compared to all the other petiole samples of the $\mathrm{BC}$ group that were extracted from the inner part of the plant. Interestingly, the outer and internal petioles of the $\mathrm{BC}$ variety are separated along the same direction discriminating the more and less mature samples of the WC and CC groups. The BC samples are isolated from the other varieties along PC3 (Figure 1b) while PC4 describes the different behavior of the BC samples according to the harvesting time (June vs. August). Figure $1 \mathrm{~b}$ also displays a neat clustering of the CC and WC samples along PC3 according to the harvesting time, and a separation, although incomplete, between the samples of these two varieties for each of the two 
harvesting dates. Inspection of Figure 2 provides information on which petiole volatiles are responsible for the trends observed in the score plot. In particular, discrimination of the WTC group with respect to the cultivated varieties can be related to a higher content of $\beta$-myrcene (having a positive loading on PC1) and lower content of $\gamma$-terpinene and limonene (both having negative loadings on PC1). The differentiation of $\mathrm{BC}$ from the other cultivated varieties along PC3 can be ascribed to higher contents of $\gamma$-terpinene, limonene, p-cymene e $\beta$-myrcene and lower contents of (Z)- $\beta$-ocimene, $(E, E)-1,3,5$-Undecatriene and $\alpha$-pinene. A decrease in p-cymene and increase in $\gamma$-terpinene contents is responsible for the separation along PC4 of the BC samples harvested in August and in June. According to the reciprocal position along the PC2 and PC4 directions of WC and CC samples collected in different months, the relatively high positive loadings of limonene on both PCs suggest an increase of this volatile components in the samples of July compared to those of February, accompanied by a decrease in the contents of Z- $\beta$-ocimene, (E,E)-1,3,5-Undecatriene and $\alpha$-pinene (showing negative loadings on PC3). On the other hand, the effect of the sampling time on the content of $\mathrm{p}$-cymene and $\gamma$-terpinene is not so obvious because the loadings of both variables on PC2 and PC3 have opposite signs.

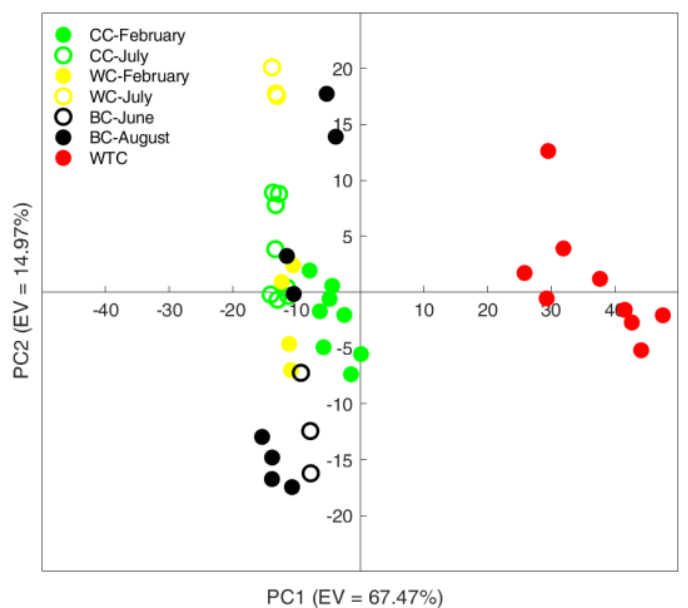

(a)

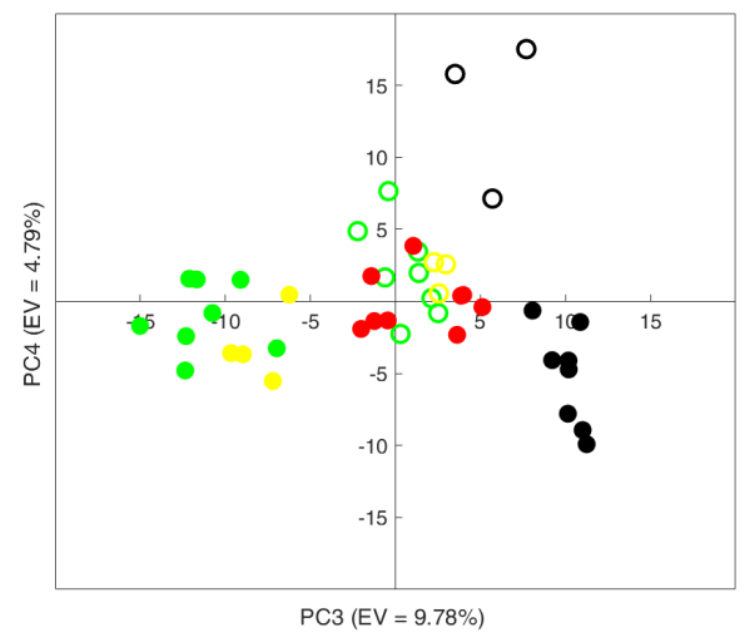

(b)

Figure 1. Projection of the celery samples: (a) on the PC1-PC2 plane; (b) on the PC3-PC4 planes. PCA analysis was carried out on the percentage areas of petiole volatiles after data centering.

\subsection{Multivariate Statistical Analysis of Leaf Volatile Profiles}

The PCA exploration of the volatile profiles of celery leaves, after data centering, is displayed in Figure 3. The score plot for the first two components (Figure 3a), explaining $99 \%$ of the total variance, reveals a neat clustering of WTC and BC samples and a differentiation of WC and CC groups according to the month of collection. Differentiation of WTC along PC1 is mainly due to the increase of $\beta$-myrcene and the decrease of limonene and $(Z)-\beta$-ocimene, according to the loadings of these variables on PC1 (Figure $3 b$ ). The discrimination of $B C$ along PC2 is related to a decrease of (Z)- $\beta$-ocimene content and to the increase of limonene and, to a lesser extent, of $\gamma$-terpinene and $p$-cimene. 


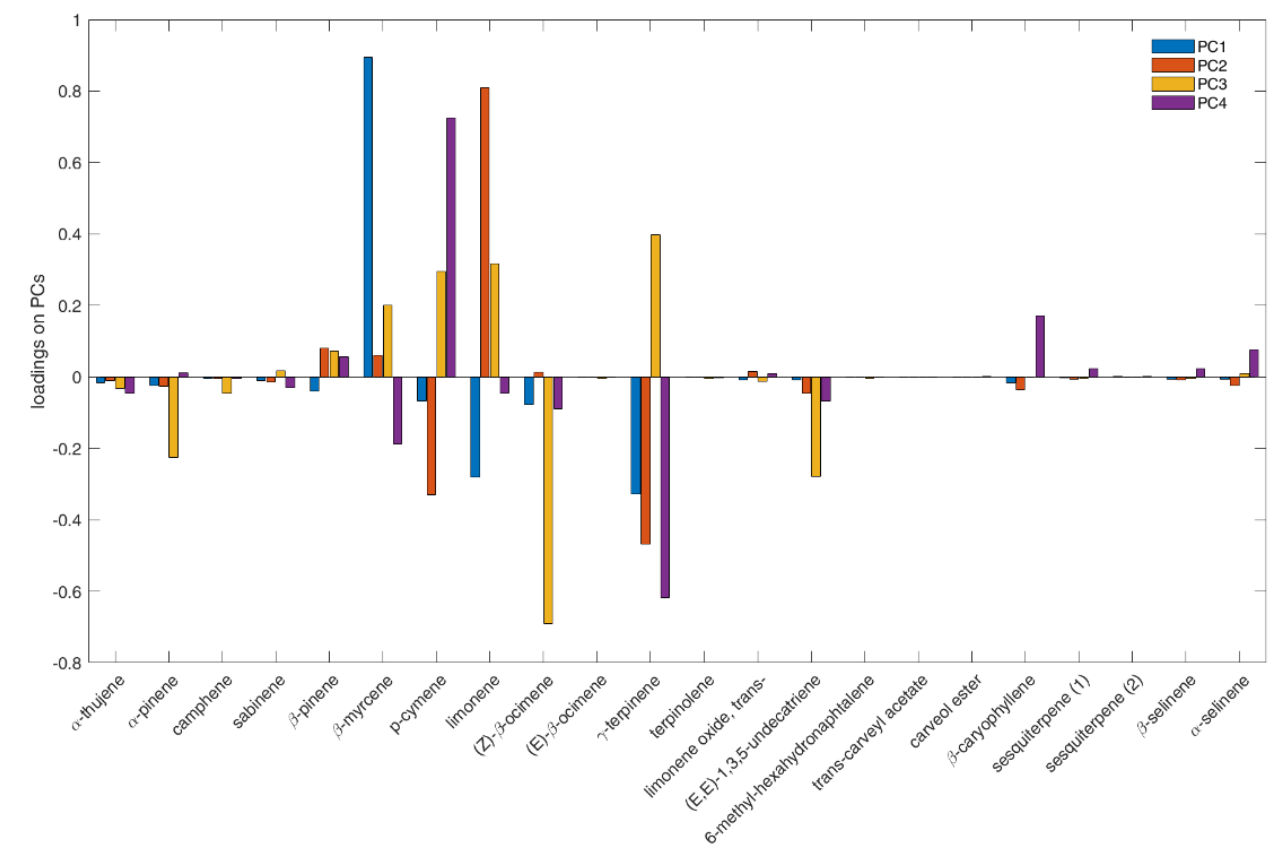

Figure 2. Variable loadings on the first four PCs extracted from the centered percentage peak areas provided by celery petiole volatiles.

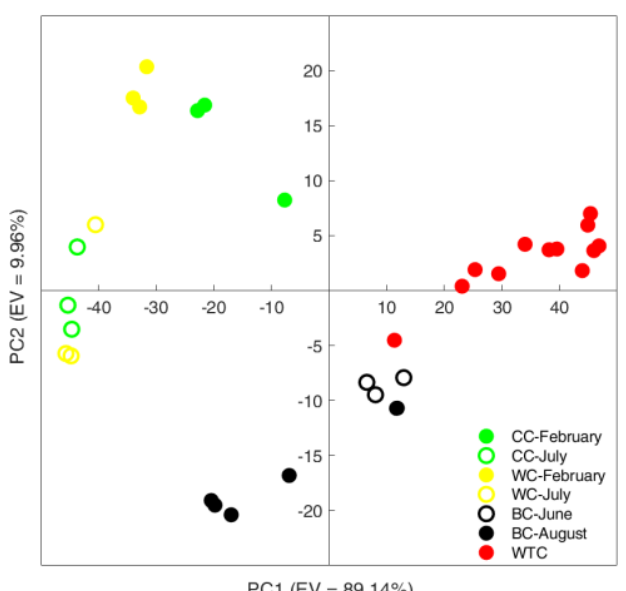

(a)

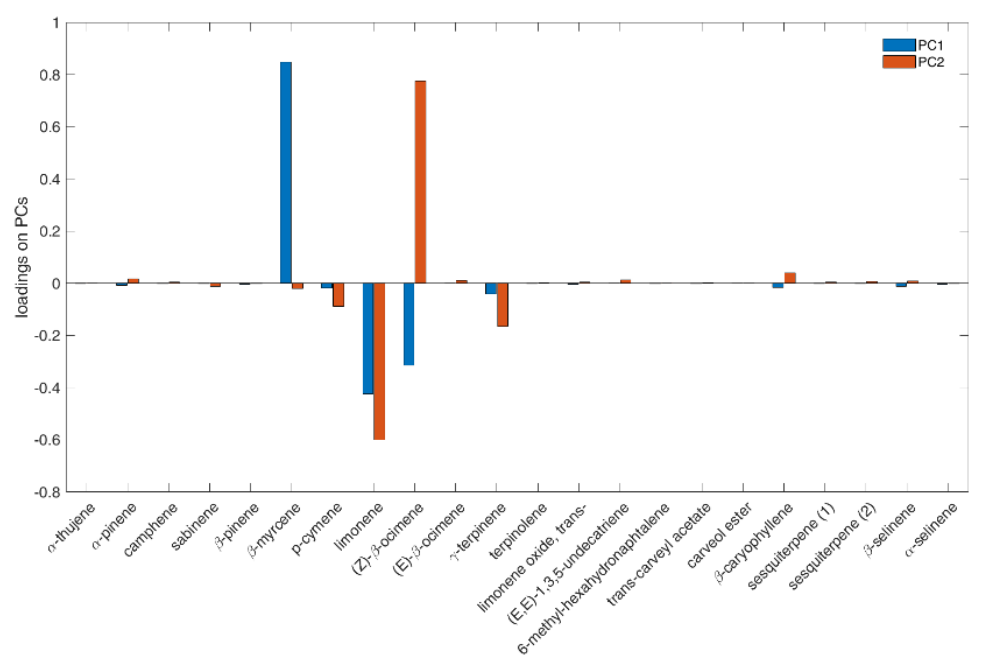

(b)

Figure 3. PCA on the volatile profiles of celery leaves after data centering: (a) projection of the samples on the PC1-PC2 plane; (b) variable loadings.

To exalt the role of low-variance variables in the discrimination of celery leaf volatile profiles, PCA was repeated on the auto-scaled data. The results are summarized in Figure 4, showing the score plots (Figure $4 \mathrm{a}, \mathrm{b}$ ) and the loading plots (Figure $4 \mathrm{c}, \mathrm{d}$ ) of the first four PCs, explaining $68.7 \%$ of total variance. Inspection of the PC1-PC2 score plot reveals two well isolated groups collecting the BC and WTC samples in the first and in the fourth quadrants, respectively. In addition, both CC and WC have negative scores on PC1 and are discriminated along this component according to the harvesting month. The PC3-PC4 score plot reveals the discrimination between WC and CC samples along the bisect of PC3 and PC4, while the differentiation of the BC samples according to the harvesting time occurs approximately along PC4 (Figure 4b). In the same plot, BC samples collected in June and in August are also well separated, approximately along PC4. The loading plots (Figure 4c,d) display which variables are responsible for the observed trends in the samples. 
For instance, the content of the volatiles $\beta$-pinene, $(E, E)-1,3,5$-undecatriene and $\beta$-myrcene is higher in the WTC samples, whereas sabinene, $\alpha$-thujene and $\alpha$-selinene, together with limonene, exhibit higher concentrations in the $\mathrm{BC}$ samples.

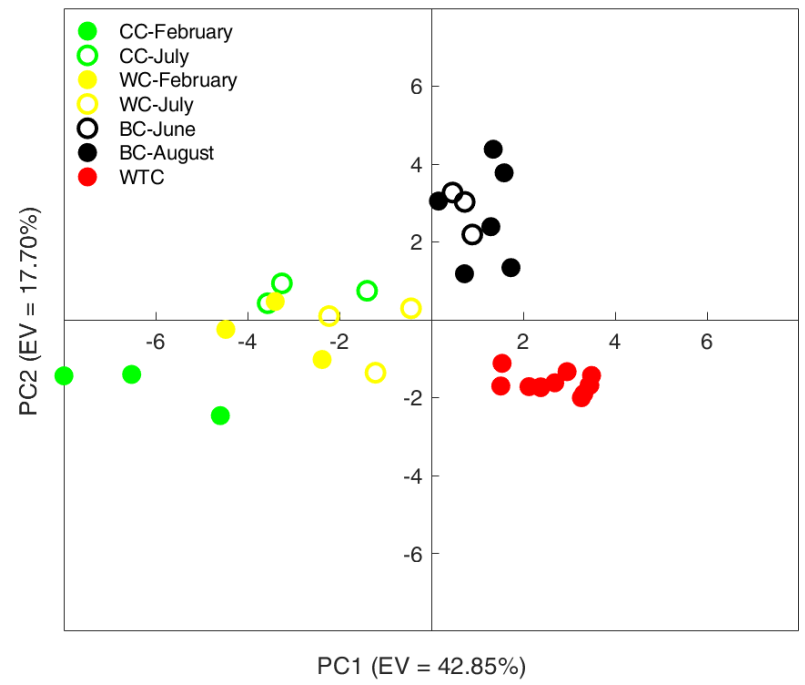

(a)

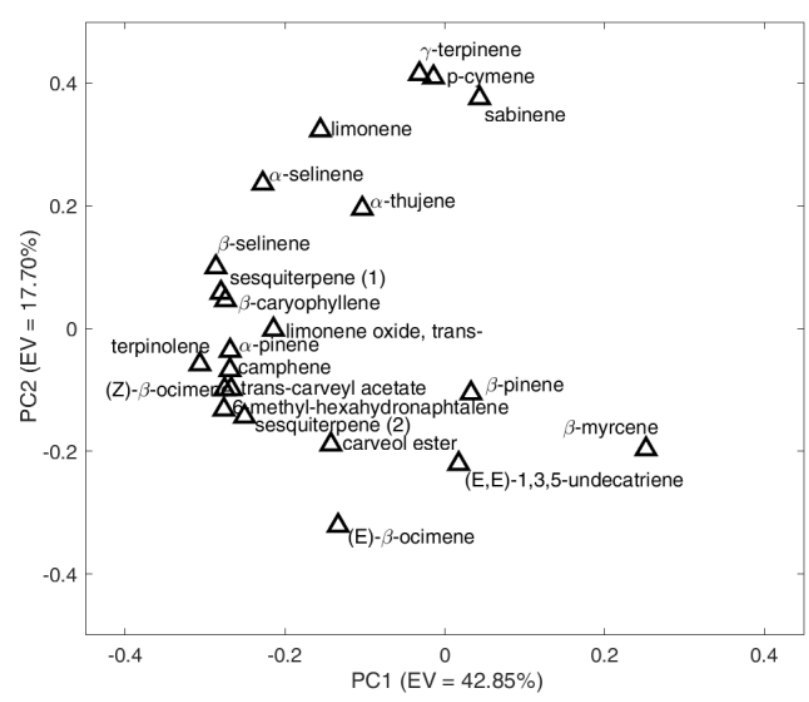

(c)

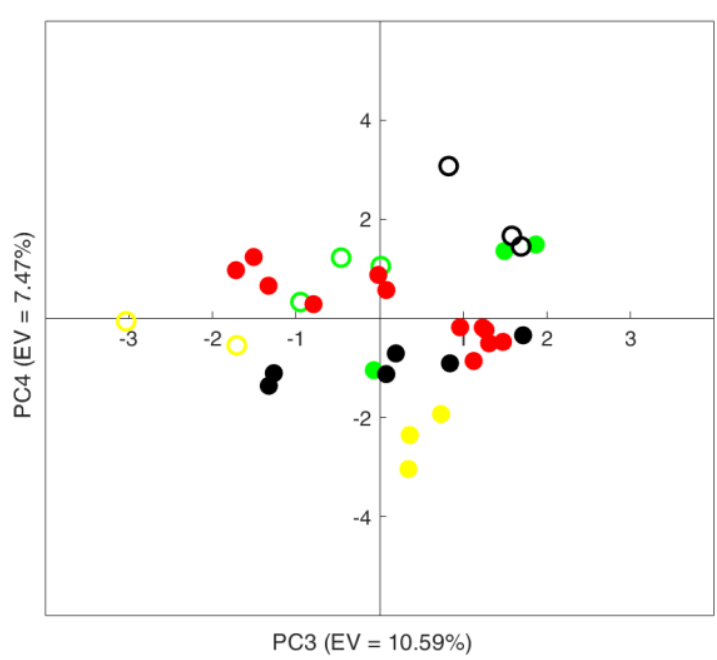

(b)

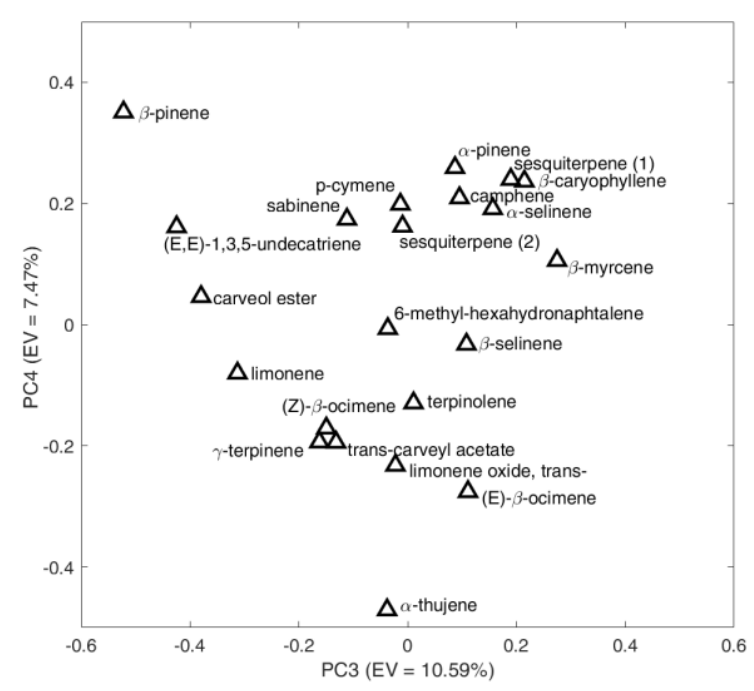

(d)

Figure 4. PCA on the volatile profiles of celery leaves after data autoscaling: (a) projection of the samples on the PC1-PC2 plane; (b) projection of the samples on the PC3-PC4 plane; (c) projection of the variable loadings on the PC1-PC2 plane; (d) projection of the variable loadings on the PC3-PC4 plane.

\section{Discussion}

The mean volatile profiles of the celery petioles and leaves of the investigated varieties (Table 1) and the PCA exploration of the HS-SPME/GC-MS data matrix has revealed that the composition of the celery aroma profile, not only is dependent on the variety/origin of this vegetable, but is also affected by the harvesting month. We expect that the different behavior of the CC and WC samples collected in February and July are due to a different maturity of the plants. It must be noted that the effect of the maturity on the petiole flavor was previously evaluated by sensory analysis through a comparison of samples collected after three and four months from celery transplantation [31], but the sensory 
panel did not perceive any significant effect. This may be explained by the lower difference in the harvesting time compared to the time range explored in the present work along with the lower sensitivity of the sensory analysis compared to the HS-SPME/GC-MS volatile profiling.

As expected, the wild form of celery (WTC) exhibits a noticeably dissimilar volatile profile compared to that of the cultivated varieties. The most relevant difference in the aroma composition is due to a higher content of $\beta$-myrcene and lower contribution of limonene and $\gamma$-terpinene. Apart from the relative contribution of the individual chemical species, the overall absolute quantity of volatile compounds released by both petioles and leaves of the wild form is considerably greater compared to that of the same parts collected from the cultivated plants.

Among the cultivated varieties, the differences in the volatile profiles of WC and CC samples are subtle although detectable, especially in the leaves. The aroma profile composition of these two varieties is also significantly dependent on the maturity of the plant. Moreover, such source of variability seems to be comparable or greater than that due to the variety. Among the cultivated varieties, BC exhibits a quite peculiar aroma composition, according to significantly higher content of $\beta$-myrcene, $\mathrm{p}$-cymene and $\gamma$ terpinene and lower content of (Z)- $\beta$-ocimene, $\alpha$-pinene and $\beta$-pinene. This makes easy the discrimination of this variety from both $\mathrm{CC}$ and WC. The composition of the aroma profile of both BC petioles and leaves is also affected by the maturity of the plant and we observed that inner and outer petioles extracted from the same celery plant exhibit different aroma profiles. Nevertheless, despite the variability related to the petiole maturity can increase the intra-class dispersion, the group of $\mathrm{BC}$ samples are neatly isolated from the other varieties.

Focusing on the volatile profiles of the celery petioles, i.e., the part consumed fresh, and on the major components, which are expected to contribute the most to their aroma as perceived by the consumers, possible differences in the sensorial attributes of the cultivated varieties can be predicted based on the known aroma descriptors of the discriminant volatiles [14]. As discussed above, the observed difference between the composition of the volatile profiles of CC and WC is relatively small, therefore, a subtle difference between the sensorial properties of these varieties must also be expected. As for BC, the higher content of $\beta$-myrcene (balsam, fruity), p-cymene (cumin, lemon) and $\gamma$-terpinene (sweet, citrus) and the lower content of $(Z)$ - $\beta$-ocimene (warm, floral, herbal) and $\alpha$-pinene (fresh, woody) and $\beta$-pinene (green, nutmeg) compared to the other two cultivated varieties, suggests that BC ecotype has a peculiar aroma that makes it easily distinguishable from the other varieties available in the market.

\section{Conclusions}

HS-SPME/GC-MS investigation of the volatile aroma profile of celery, which is closely related to the sensorial attributes of this vegetable, offers a very accurate tool for the varietal/origin discrimination. The composition of the volatile profile is also potentially useful to discriminate the celery petioles according to the harvesting time. A future extension of the present study may focus on the development of classification/modeling approaches for the authentication of celery varieties with a strong geographical/varietal identity.

Author Contributions: Conceptualization, A.A.D. and L.D.M.; methodology, S.R. and F.D.D.; software, F.D.D.; formal analysis, S.R. and F.D.D.; investigation, S.R. and F.D.D.; resources, V.D.C., A.M. and M.D.S.; data curation, S.R., A.M. and V.D.C.; writing-original draft preparation, S.R. and A.A.D.; writing-review and editing, A.A.D.; project administration, M.D.S. and L.D.M.; funding acquisition, L.D.M. All authors have read and agreed to the published version of the manuscript.

Funding: This research was funded by Majella National Park within the Project "Tipizzazione di specie vegetali endemiche, crop wild relatives e varietà agricole autoctone del Parco della Majella mediante metodi analitici ed approcci statistici multivariati" with the Dipartimento di Scienze Fisiche e Chimiche, Università degli Studi dell'Aquila. 
Institutional Review Board Statement: Not applicable.

Informed Consent Statement: Not applicable.

Data Availability Statement: Not applicable.

Conflicts of Interest: The authors declare no conflict of interest.

\section{References}

1. Torricelli, R.; Tiranti, B.; Spataro, G.; Castellini, G.; Albertini, E.; Falcinelli, M.; Negri, V. Differentiation and structure of an Italian landrace of celery (Apium graveolens L.): Inferences for on farm conservation. Genet. Resour. Crop. Evol. 2013, 60, 995-1006. [CrossRef]

2. Manzi, A. I Progenitori Delle Piante Coltivate in Italia. I Parenti Selvatici Dei Vegetali in Coltura Per Uso Alimentare, Il Processo di Domesticazione E La Salvaguardia; Meta Edizioni: Treglio, Italy, 2020.

3. Bruznican, S.; De Clercq, H.; Eeckhaut, T.; Van Huylenbroeck, J.; Geelen, D. Celery and Celeriac: A Critical View on Present and Future Breeding. Front. Plant. Sci. 2020, 10, 1-12. [CrossRef]

4. Raffo, A.; Sinesio, F.; Moneta, E.; Nardo, N.; Peparaio, M.; Paoletti, F. Internal quality of fresh and cold stored celery petioles described by sensory profile, chemical and instrumental measurements. Eur. Food Res. Technol. 2006, 222, 590-599. [CrossRef]

5. Yao, Y.; Sang, W.; Zhou, M.; Ren, G. Phenolic composition and antioxidant activities of 11 celery cultivars. J. Food Sci. 2010, 75, C9-C13. [CrossRef]

6. Liu, G.; Zhuang, L.; Song, D.; Lu, C.; Xu, X. Isolation, purification, and identification of the main phenolic compounds from leaves of celery (Apium graveolens L. var. dulce Mill./Pers.). J. Sep. Sci. 2017, 40, 472-479. [CrossRef]

7. Kooti, W.; Daraei, N. A Review of the Antioxidant Activity of Celery (Apium graveolens L.). J. Evidence-Based Complement. Altern. Med. 2017, 22, 1029-1034. [CrossRef] [PubMed]

8. Han, D.; Row, K.H. Determination of luteolin and apigenin in celery using ultrasonic-assisted extraction based on aqueous solution of ionic liquid coupled with HPLC quantification. J. Sci. Food Agric. 2011, 91, 2888-2892. [CrossRef] [PubMed]

9. Tsi, D.; Tan, B.K.H. The Mechanism Underlying the Hypocholesterolaemic. Life Sci. J. 2000, 66, 755-767. [CrossRef]

10. Ovodova, R.G.; Golovchenko, V.V.; Popov, S.V.; Popova, G.Y.; Paderin, N.M.; Shashkov, A.S.; Ovodov, Y.S. Chemical composition and anti-inflammatory activity of pectic polysaccharide isolated from celery stalks. Food Chem. 2009, 114, 610-615. [CrossRef]

11. Mišić, D.; Zizovic, I.; Stamenić, M.; Ašanin, R.; Ristić, M.; Petrović, S.D.; Skala, D. Antimicrobial activity of celery fruit isolates and SFE process modeling. Biochem. Eng. J. 2008, 42, 148-152. [CrossRef]

12. Sultana, S.; Ahmed, S.; Jahangir, T.; Sharma, S. Inhibitory effect of celery seeds extract on chemically induced hepatocarcinogenesis: Modulation of cell proliferation, metabolism and altered hepatic foci development. Cancer Lett. 2005, 221, 11-20. [CrossRef]

13. Boonruamkaew, P.; Sukketsiri, W.; Panichayupakaranant, P.; Kaewnam, W.; Tanasawet, S.; Tipmanee, V.; Hutamekalin, P.; Chonpathompikunlert, P. Apium graveolens extract influences mood and cognition in healthy mice. J. Nat. Med. 2017, 71, 492-505. [CrossRef] [PubMed]

14. Turner, L.; Lignou, S.; Gawthrop, F.; Wagstaff, C. Investigating the factors that influence the aroma profile of Apium graveolens: A review. Food Chem. 2021, 345, 128673. [CrossRef]

15. Tirillini, B.; Pellegrino, R.; Pagiotti, R.; Pocceschi, N.; Menghini, L. Volatile compounds in different cultivars of Apium graveolens L. Ital. J. Food Sci. 2004, 16, 477-482.

16. Liu, D.K.; Xu, C.C.; Zhang, L.; Ma, H.; Chen, X.J.; Sui, Y.C.; Zhang, H.Z. Evaluation of bioactive components and antioxidant capacity of four celery (Apium graveolens L.) leaves and petioles. Int. J. Food Prop. 2020, 23, 1097-1109. [CrossRef]

17. Lau, H.; Laserna, A.K.C.; Li, S.F.Y. 1H NMR-based metabolomics for the discrimination of celery (Apium graveolens L. var. dulce) from different geographical origins. Food Chem. 2020, 332, 127424. [CrossRef] [PubMed]

18. European Commission: eAmbrosia, the EU Geographical Indications Register. Available online: http:/ / ec.eurohttps/ / ec.europa. eu/info/food-farming-fisheries/food-safety-and-quality/certification/quality-labels/geographical-indications-register/ (accessed on 12 May 2021).

19. Ingallina, C.; Capitani, D.; Mannina, L.; Carradori, S.; Locatelli, M.; Di Sotto, A.; Di Giacomo, S.; Toniolo, C.; Pasqua, G.; Valletta, A.; et al. Phytochemical and biological characterization of Italian "sedano bianco di Sperlonga" Protected Geographical Indication celery ecotype: A multimethodological approach. Food Chem. 2020, 309, 125649. [CrossRef]

20. Di Donato, F.; Di Cecco, V.; Torricelli, R.; D’Archivio, A.A.; Di Santo, M.; Albertini, E.; Veronesi, F.; Garramone, R.; Aversano, R.; Marcantonio, G.; et al. Discrimination of potato (Solanum tuberosum L.) accessions collected in Majella National Park (Abruzzo, Italy) using mid-infrared spectroscopy and chemometrics combined with morphological and molecular analysis. Appl. Sci. 2020, 10, 1630. [CrossRef]

21. Di Cecco, V.; Di Santo, M.; Di Musciano, M.; Manzi, A.; Di Cecco, M.; Ciaschetti, G.; Marcantonio, G.; Di Martino, L. The Majella national park: A case study for the conservation of plant biodiversity in the Italian apennines. Ital. Bot. 2020, 10, 1-24. [CrossRef]

22. Belliardo, F.; Bicchi, C.; Cordero, C.; Liberto, E.; Rubiolo, P.; Sgorbini, B. Headspace Solid-Phase Microextraction in the Analysis of Aromatic and Medicinal Plants. J. Chromatogr. Sci. 2006, 44, 416-429. [CrossRef]

23. Merkle, S.; Kleeberg, K.; Fritsche, J. Recent Developments and Applications of Solid Phase Microextraction (SPME) in Food and Environmental Analysis-A Review. Chromatography 2015, 2, 293-381. [CrossRef] 
24. Souza-Silva, É.A.; Gionfriddo, E.; Pawliszyn, J. A critical review of the state of the art of solid-phase microextraction of complex matrices II. Food analysis. TrAC Trends Anal. Chem. 2015, 71, 236-248. [CrossRef]

25. Guijarro-Real, C.; Rodríguez-Burruezo, A.; Prohens, J.; Raigón, M.D.; Fita, A. HS-SPME analysis of the volatiles profile of water celery (Apium nodiflorum), a wild vege with increasing culinary interest. Food Res. Int. 2019, 121, 765-775. [CrossRef] [PubMed]

26. NIST14. Mass Spectral Database; NIST: Gaithersburg, MD, USA.

27. Adams, R.P. Identification of Essential Oil Components by Gas. Chromatography/Mass Spectrometry, 4th ed.; Allured Publishing: Carol Stream, IL, USA, 2007.

28. Wold, S. Principal component analysis. Chemom. Intell. Lab. Syst. 1987, 2, 37-52. [CrossRef]

29. Tu, H.; Qin, Y. Repellent Effects of Different Celery Varieties in Bemisia tabaci (Hemiptera: Aleyrodidae) Biotype Q. J. Econ. Entomol. 2017, 110, 1307-1316. [CrossRef]

30. Bjeldanes, L.S.; Kim, I.-S. Phthalide components of celery essential oil. J. Org. Chem. 1977, 42, 2333-2335. [CrossRef]

31. Guerra, N.; Carrozzi, L.; Goñi, M.G.; Roura, S.; Yommi, A. Quality characterization of celery (Apium graveolens L.) by plant zones and two harvest dates. J. Food Sci. 2010, 75, S327-S332. [CrossRef] [PubMed] 